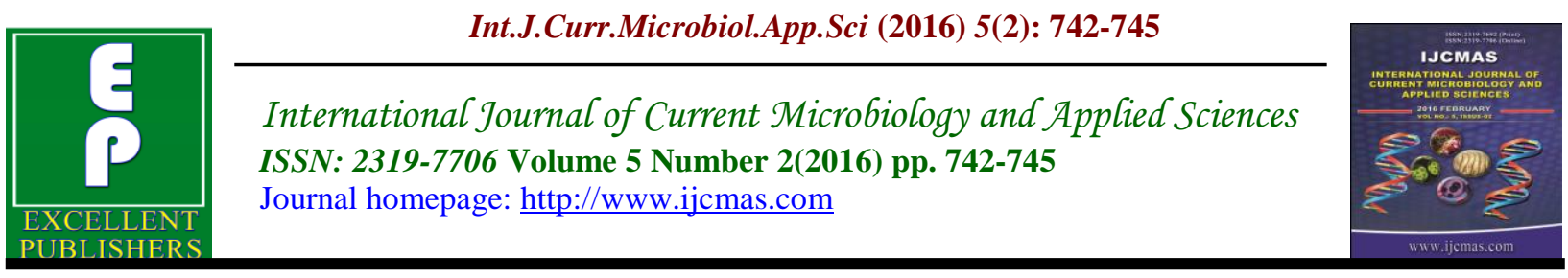

Original Research Article

doi: http://dx.doi.org/10.20546/ijcmas.2016.502.083

\title{
Mikania Micrantha - a Natural Remedy to Skin Infections
}

\author{
Madhavankutty Jyothilakshmi ${ }^{1}$, Mathew Jyothis ${ }^{2}$ and Mukalel Sankunni Latha ${ }^{1}$ * \\ ${ }^{1}$ Biochemistry and Pharmacognosy Research lab, School of Biosciences, Mahatma Gandhi \\ University, Kottayam, Kerala, India \\ ${ }^{2}$ Microbiology Research lab, School of Biosciences, Mahatma Gandhi University, \\ Kottayam, Kerala, India \\ *Corresponding author
}

\begin{abstract}
A B S T R A C T
Keywords

Antidermatophytic activity, Anti-inflammatory activity, Antibacterial activity, Protease, trypsin.

Article Info

Accepted:

28 January 2016

Available Online:

10, February 2016

Dermatophytoses and bacterial infections by Staphylococcus aureus and Streptococcus pyogenes are among the major infectious diseases of the skin. Mikania micrantha - a tropical herb has been found to possess antidermatophytic activity and anti-inflammatory activity in a screening study. Hence its antibacterial activity against S.aureus and S.pyogenes was tested by disc diffusion method using the ethyl acetate extract. The extract possessed moderate antibacterial activity against both organisms. Minimum inhibitory concentration and minimum fungicidal concentration were determined according to CLSI method. Thus the combined antibacterial, antifungal and anti-inflammatory activities make Mikania micrantha a good candidate for developing new drugs for skin infections.
\end{abstract}

\section{Introduction}

Mikania micrantha is a perennial herb belonging to the family Asteraceae. It is native to Central and South America but it is now widely distributed in India, South china, Southeast Asia, Pacific islands etc (Peerez Amador et al., 2010). The plant is used in traditional medicine by people of Africa, Jamaica and Guyana Patanoma for skin diseases, wound dressings, chicken pox etc. (Ayensu, 1981; Facey, 1999). Dermatophytoses and bacterial infections by Staphylococcus aureus and Streptococcus pyogenes are among the major infectious diseases of the skin.
In a previous study Mikania micrantha was found to possess activity against dermatophytes causing dermatophytoses, the major fungal disease of the skin (Jyothilakshmi et al., 2015). Hence the present study was designed to evaluate the activity of the plant against Staphylococcus aureus and Streptococcus pyogenes, the major bacterial pathogens of the skin.

\section{Materials and Methods}

\section{Plant Material}

Leaves and flowers (inflorescence with 
seeds) of Mikania micrantha were collected from the district of Kottayam, Kerala, washed, shade dried and powdered in a kitchen blender. The plant was identified by a plant taxonomist and a voucher specimen (SBSBRL 19) has been maintained with the author's institute.

\section{Microorganisms and Media}

The following bacteria were purchased from MTCC, Institute of Microbial technology, Chandigarh.

Staphylococcus aureus - MTCC 1927

Streptococcus pyogenes - MTCC 3160

Staphylococcus aureus was subcultured and maintained on nutrient agar medium and Streptococcus pyogenes on Brain Heart Infusion medium (HiMedia).

\section{Extraction of Plant Material}

The powdered leaves and flowers were extracted with ethyl acetate at room temperature in an orbital shaker for seven days, filtered, evaporated to dryness and stored in sterile bottles until use.

\section{Antibacterial Activity}

Antibacterial activity was first tested by disc diffusion method according to the method of CLSI M02 - A11 (CLSI, 2012a). MuellerHinton agar (HiMedia) was used for Staphylococcus aureus and Brain Heart Infusion agar for Streptococcus pyogenes. The extracts were dissolved in DMSO $(10 \mu \mathrm{g} / \mu \mathrm{L})$ and sterile discs were impregnated with $200 \mu \mathrm{g}(20 \mu \mathrm{L})$ of test materials. Inoculum was prepared in nutrient broth for Staphylococcus aureus and Brain Heart Infusion medium for Streptococcus pyogenes. Disc impregnated with equal volume of DMSO was used as negative and Penicillin G disc (2units/disc) as positive control.
The Minimum Inhibitory concentration of the extracts was determined according to CLSI M07-A9 (CLSI, 2012b) with slight modification. Muller-Hinton broth was used for Staphylococcus aureus and Brain Heart Infusion medium for Streptococcus pyogenes. Test was performed within the concentration range $31.25-1000 \mu \mathrm{g} / \mathrm{mL}$ of medium. In order to determine the bactericidal activity $10 \mu \mathrm{L}$ from tubes with no growth was sub cultured on respective agar plates and incubated at $37^{\circ} \mathrm{C}$ overnight.

\section{Results and Discussion}

The zone of inhibitions exhibited by ethyl acetate extract of both the leaves (ELMM) and flowers (EFMM) were $15 \mathrm{~mm}$ and 17 $\mathrm{mm}$ for Staphylococcus aureus and Streptococcus pyogenes respectively (Figure 1) while that of Penicillin $G$ was $50 \mathrm{~mm}$ and $43 \mathrm{~mm}$ respectively. MIC and MBC of both the extracts were $500 \mu \mathrm{g} / \mathrm{mL}$ and 1000 $\mu \mathrm{g} / \mathrm{mL}$ respectively for both the organisms.

Keratinized surface, low $\mathrm{pH}$, high salt content and presence of lysozyme make the skin hostile for microorganisms. But the bacteria Staphylococcus aureus and Streptococcus pyogenes are suited to living on skin and sometimes cause infections. Most strains of Staphylococcus aureus are relatively low virulent and harmless if the infection is restricted to superficial layers of intact skin. But they cause infection once they gain entry into damaged skin. Streptococcus pyogenes is also capable of causing infection on damaged skin (Cowan and Talaro, 2006; Jensen et al., 1997). Impetigo, cellulitis, hair follicle infections, Staphylococcal scaled syndrome and necrotizing fasciitis are the major skin diseases caused by Staphylococcus aureus. Impetigo, cellulitis, erysipelas and necrotizing fasciitis are the major skin diseases caused by Streptococcus pyogenes. 
Figure.1 Antibacterial Activity of Ethyl Acetate Extract of Leaves and Flowers of Mikania Micrantha - Disc Diffusion Method

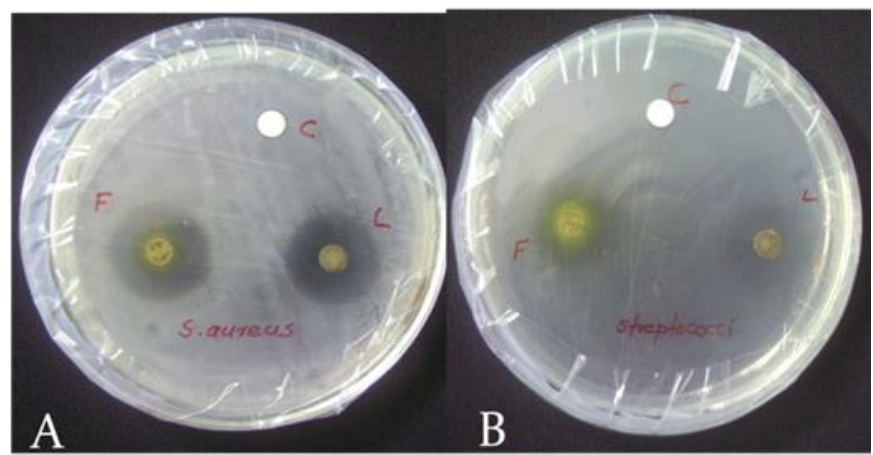

A - Staphylococcus aureus, B-Streptococcus pyogenes. C - control, F - extract of flower and $\mathrm{L}$ - extract of leaves

These infections in immunocompromised or improperly treated patients can be complicated and may give rise to systemic diseases. Dermatophytoses produce large areas of injured skin which may provide easy route for the entry of these bacterial pathogens. A topical agent providing both antidermatophytic and antibacterial activity will be beneficial in such cases.

The plant also has been reported to possess trypsin inhibiting activity (Jyothilakshmi et al., 2015) which is an indicator of its antiinflammatory property. Since inflammation is usually associated with bacterial skin infections and dermatophytoses, combined antibacterial, antifungal and antiinflammatory activities make Mikania micrantha a potential source of active principle useful for developing new drugs for skin infections.

\section{Acknowledgement}

Authors are thankful to Mahatma Gandhi University for the Junior Research Fellowship to the author Jyothilakshmi M (U.O.No: 5175/AVI/JRF/2014/Acad dated 08/09/2015).

\section{References}

Ayensu, ES. 1981. Medicinal Plants of the West Indies. Algonac, Michigan: Reference Publications Inc.

CLSI. 2012 a. Performance Standards for Antimicrobial Disk Susceptibility Tests; Approved Standard-Eleventh Edition. CLSI document M02-A11. Wayne, PA: Clinical and Laboratory Standards Institute.

CLSI. 2012 b. Methods for Dilution Antimicrobial Susceptibility Tests for Bacteria That Grow Aerobically; Approved Standard-Ninth Edition. CLSI document M07-A9. Wayne, PA: Clinical and Laboratory Standards Institute.

Cowan, MK., Talaro, KP. 2006. Microbiology A systems approach. New York: Mc Graw-Hill International foundation.

Facey, PC., Pascoe, KO., Porter, RB., Jones, AD. 1999. Investigation of plants used in Jamaican folk medicine for anti-bacterial activity. Journal of Pharmacy and Pharmacology. 51(12):1455-1460.

Jensen, MM., Wright, DN., Robison, RA. 1997. Microbiology for the Health 
Sciences, 4th edition. Upper Saddle River, New Jersey: Prentice-Hall Inc. Jyothilakshmi, M., Jyothis, M., Latha, MS. 2015. Antidermatophytic activity of Mikania micrantha Kunth - An Invasive Weed. Pharmacognosy Research. 7(Suppl 1): S20-S25.
Balcazar, RI., Jimenez, FG. 2010. Phytochemical and pharmacological studies on Mikania micrantha H.B.K. PHYTON-International Journal of Experimental Botany. 79: 77-80.

Perez-Amador, MC., Ocotero, VM.,

\section{How to cite this article:}

Madhavankutty Jyothilakshmi, Mathew Jyothis and Mukalel Sankunni Latha. Mikania Micrantha - a Natural Remedy to Skin Infections. Int.J.Curr.Microbiol.App.Sci.5(2): 742-745. doi: http://dx.doi.org/10.20546/ijcmas.2016.502.083 